\title{
TRATAMIENTO DE LA NORMA SOCIETARIA DESDE LA PERSPECTIVA ECONÓMICA HARD LAW VS SOFT LAW
}

\section{TREATMENT OF THE CORPORATE RULE FROM THE ECONOMIC PERSPECTIVE HARD LAW VS SOFT LAW}

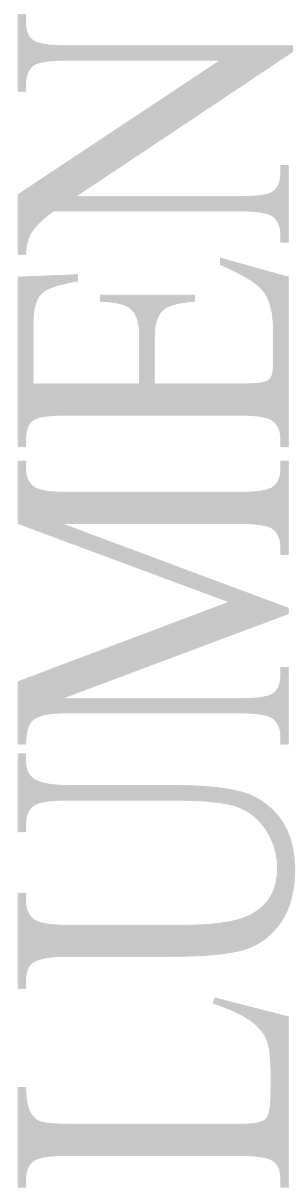




\title{
TRATAMIENTO DE LA NORMA SOCIETARIA DESDE LA PERSPECTIVA ECONÓMICA HARD LAW VS SOFT LAW
}

\author{
TREATMENT OF THE CORPORATE RULE FROM THE ECONOMIC \\ PERSPECTIVE HARD LAW VS SOFT LAW
}

\section{RESUMEN}

Enrique Vigil Oliveros

El presente artículo tiene como idea principal analizar la repercusión de las normas societarias descritas en la Ley General de Sociedades vigente en nuestra sociedad para la constitución, funcionamiento y salida ordenada del mercado. La realidad económica en nuestro país pareciera que no se condice con la realidad jurídica, encontrándose incluso en varias disposiciones un divorcio entre estas dos ciencias que desencadena perjuicios a las corporaciones por la demora en los trámites que acarrean pérdidas económicas.

En este artículo, el análisis buscará la posible solución a través de la superación de las deficiencias en las normas societarias con la construcción de normas permisivas para el mejor desarrollo empresarial en el mercado nacional.

\section{PALABRAS CLAVE}

Sociedad, realidad jurídica, realidad económica, mercado, normas

\begin{abstract}
The main purpose of this article is to analyze the impact of the corporate rules described in the General Corporation Law in force in our company for the constitution, operation and orderly exit of the market. The economic reality in our country seems not to be consistent with the legal reality, even being in several provisions a divorce between these two sciences that unleashes damage to societies in the delay in procedures that result in economic losses.

In this article, the analysis will seek the solution through overcoming the deficiencies of corporate norms by building permissive standards for the best business development.
\end{abstract}

\section{KEY WORDS}

Society, legal reality, economic reality, market, norms.

\section{INTRODUCTION}

Las normas societarias establecidas en nuestra Ley General de Sociedades, son producto de las interpretaciones de las diversas doctrinas que establece el civil law, entre ellas las escuelas alemana, francesa, italiana y española. Sin embargo, si bien es cierto existió la noble intención de la Comisión Revisora de la Ley, conformada por connotados juristas, nuestra realidad económica y social, permite establecer que nuestra Ley no se encuentra acorde a los nuevos cambios económicos y la rigurosidad en las normas ocasionan perjuicios económicos a las sociedades.

En algunas ocasiones el ámbito jurídico, a diferencia del lenguaje común de las personas, puede ser un poco reservado para adaptar una posición legal adecuada, ya que para sustentar ciertas 
pretensiones que deseamos solicitar debemos recurrir al instrumento normativo; sin embargo, lamentablemente en algunas ocasiones la ley puede demostrar vacíos o lagunas susceptibles de tergiversar los reales requerimientos de la sociedad o la voluntad de los socios.

Es por ello, que las normas deben ser diseñadas para regular las conductas, en nuestro análisis económico-social y, por ello, no deben surgir problemas de interpretación al momento de aplicarlas.

En este orden de ideas, es preciso señalar a la Dra. Gascón, quien considera que el punto de partida de la concepción intermedia es la toma de conciencia del carácter discrecional de la interpretación, y por consiguiente del componente ideológico o subjetivo que está presente en la misma, sobre todo cuando aparecen dudas o problemas interpretativos. ${ }^{1}$

"La discrecionalidad se manifiesta cuando la interpretación aparece como dudosa o problemática. Las principales dudas o problemas interpretativos que pueden presentarse se ligan a los tres contextos siguientes: (i) en el contexto lingüístico, cuando un determinado texto será interpretado según las reglas generales del lenguaje por el cual se concibe esta comunicación, lo cual podría ser llamado lenguaje natural; (ii) en el contexto sistémico, cuando se pretender recurrir a un sistema esquematizado para poder entender el lenguaje o la comunicación misma a la que se quiere llegar, como por ejemplo en el ámbito legal que resulta ser amplio, de manera que su interpretación ha de hacerse teniendo en cuenta sus relaciones con el resto de los elementos del sistema; y (iii) contexto funcional, la ley tiene una relación con la sociedad ya que con la ley se pretende lograr algún efecto social, de manera que cuando se interpreta una determinada normativa ha de valorarse si cumple la función o los fines para los que ha sido creada." ${ }^{2}$

Es por estas razones que la búsqueda de un significado jurídico contrastado en el campo del lenguaje puede resultar ser un poco peligroso para nuestros clientes como para nosotros mismos, ya que podríamos encontrarnos en problemas de ambigüedad, vaguedad, entre otros, que resultaría ser un problema sustancial en la aplicación de una determinada norma; la atención de estudio de la norma sometida al razonamiento jurídico y económico de la interpretación.

\section{PLANTEAMIENTO DEL PROBLEMA}

Nace una interrogante para poder definir el problema: ¿Las normas societarias están acorde con las necesidades económicas de la actividad empresarial? Existen normas jurídicas en nuestra Ley General de Sociedades que obstaculizan y en algunos casos acarrean grandes pérdidas a la empresa hasta llegar inclusive a su desaparición en el mercado. Ello se debe a que las normas societarias son en su gran mayoría de carácter riguroso, es decir son reglas imperativas de estricto cumplimiento que no dejan opción a las sociedades para elegir una estrategia más idónea en la solución de un determinado conflicto o incertidumbre. Analicemos algunos ejemplos contemplados en nuestra Ley:

El artículo $4^{\circ}$ de la Ley General de Sociedades, establece:

"La sociedad se constituye cuando menos por dos socios, que pueden ser personas naturales o jurídicas. Si la sociedad pierde la pluralidad mínima de socios y ella no se reconstituye en un plazo de seis meses, se disuelve de pleno derecho al término de ese plazo. No es exigible

MARIANA GASCÓN ABELLAN. Teoría del razonamiento y la argumentación jurídica. Tema 2: Problemas interpretativos. P. 1

2 MARIANA GASCÓN ABELLAN. Op.cit. P. 1 
pluralidad de socios cuando el único socio es el Estado o en otros casos señalados expresamente por ley."

En este caso podemos ver que en el caso de personas distintas al Estado o las que establece la Ley, siempre para constituir una sociedad se quiere mínimo dos personas sean naturales o jurídicas. Conociendo nuestra idiosincrasia y la gran cantidad de empresas que se constituyen en nuestro país, para crear una sociedad anónima que posee ciertas ventajas frente a los otros tipos societarios en algunos casos, como por ejemplo el fácil desplazamiento de capitales, a través de acciones, las personas crean una sociedad con $99.99 \%$ de capital y a otra persona le asignan el $00.01 \%$ solo con el objeto de cumplir con la pluralidad de socios y olvidando el sentido de tomar decisiones en conjunto en beneficio de la sociedad.

Pero el problema se agrava cuando por ejemplo:

Juan Maradiegue Osorio con DNI N 08975643, economista, desea crear una sociedad con la empresa JMO E.I.R.L con RUC 2050608161, que tiene como Titular a Juan Maradiegue Osorio, empresa dedicada a la fabricación de camisas. El Señor Juan Maradiegue desea constituir la sociedad para dedicarse a la venta de espárragos...

\section{¿En este caso se podrá crear la sociedad?}

La comisión revisora de la Ley General de Sociedades estableció que sí es posible crear la sociedad por cuanto si se cumple con la pluralidad de socios al ser Juan en este caso una persona natural y JMO E.I.R.L donde él es el Titular, una persona jurídica. Es decir, al momento de constituir la sociedad las firmas serán las mismas, pero de personas distintas, una como persona natural y otra como representante de la persona jurídica. Sin embargo, no se contempla en este caso el aspecto económico, por cuanto la comisión estableció que para la toma de decisiones que se realiza en la Junta General, la solución sería que JMO E.I.R.L nombre a un representante, con ello ya la Junta estaría representada por el mínimo de dos personas. Surte una pregunta: ¿esta salida es la más adecuada? ¿El representante podrá tener voz y voto autónomo? Es indudable que las respuestas son negativas. Por ello, contemplando el aspecto económico y la importancia de un tipo societario que mueva capitales a través de sociedades anónimas los países europeos y por ejemplo en América Latina, Argentina entre otros países, permiten la sociedad de una persona, por cuanto este tipo societario no se basa en la persona sino en su aporte. Con este artículo impositivo de hard law, se logra que por ejemplo un multimillonario como Bill Gates, no piense invertir como persona natural en el Perú prefiriendo por ejemplo Argentina que le permitirá sin ningún problema invertir a título personal solo interesándole que se aporte el capital. Esta es una excelente práctica de Soft Law (Derecho flexible, de normas permisivas).

Por citar otro artículo de análisis veamos el artículo 22:

"Cada socio está obligado frente a la sociedad por lo que se haya comprometido a aportar al capital. Contra el socio moroso la sociedad puede exigir el cumplimiento de la obligación mediante el proceso ejecutivo o excluir a dicho socio por el proceso sumarísimo.

El aporte transfiere en propiedad a la sociedad el bien aportado, salvo que se estipule que se hace a otro título, en cuyo caso la sociedad adquiere sólo el derecho transferido a su favor por el socio aportante. El aporte de bienes no dinerarios se reputa efectuado al momento de otorgarse la escritura pública." 
En este caso, si un socio al momento de constituir no cumple con aportar el íntegro de su aporte, por cuanto la Ley General de Sociedades, sólo exige que las sociedades de capitales suscriban el $100 \%$ del capital social pero que puedan pagar al menos el $25 \%$, comprometiéndose los socios a cumplir con el total de su aporte dentro del año de ejercicio. Si no cumpliera con su aporte, la sociedad señala el artículo precitado, podrá iniciar un proceso de exigibilidad de pago conocido en la actualidad como "proceso único de ejecución" o realizar un "proceso de exclusión de socio", en ambos casos recurrir al Poder Judicial.

Veamos el costo-beneficio de estas acciones:

"La duración de los procesos judiciales es la constante incertidumbre entre nosotros los litigantes pues la demora al resolver parece eterna si eres demandante, es en esta misma línea que se emitió un informe, La justicia en el Perú: cinco grandes problemas del grupo Gaceta Jurídica. Según el Informe, los jueces se toman treinta días para calificar una demanda además de que, en promedio, transcurren treinta días desde la fecha de la presentación de la demanda hasta que se expide el auto admisorio o de inadmisibilidad, desde un punto de vista más personal, este promedio frecuentemente es superado.

Ahora desde un punto de análisis legal, el plazo de calificación de la demanda aumenta en promedio a quince veces más de lo que señala la Ley Orgánica del Poder Judicial en su artículo $\mathrm{N}^{\circ}$ $1533^{3}$

"La estadística no está poco justificada pues existe una excesiva carga procesal, es así que en el 2018 se registró una carga de 3'159,446. De estos, 2'593,132 son expedientes que estaban en trámite, mientras que 566,314 se encontraban en el plazo de impugnación. De los 2'593,132 de expedientes que estaban en trámite, 1'507,204 son expedientes nuevos (ingresos), mientras que 1 '085,928 corresponden a la carga de años anteriores."

"Otros datos relevantes: en los juzgados de paz letrado existían el año pasado 345,253 expedientes en trámite y 303,228 se encontraban en plazo de impugnación. La carga procesal ascendía a 811,765, lo cual determinaba una tasa de congestión del 1,57.

En el caso de los juzgados especializados o mixtos, en el 2018 existían 653,119 procesos en trámite y 259,028 en plazo de impugnación. La carga procesal ascendía a 1'509,697, con una tasa de congestión del 1,64.

Finalmente, en el caso de las salas superiores, los procesos en trámite ascendían a 87,556, mientras que 4,058 se encontraban en plazo de impugnación. Asimismo, la carga procesal era de 271,670 , con una tasa de congestión de 1,56."

Como vemos con esta norma de Hard Law (derecho rígido, de normas imperativas), sólo la sociedad para que sea admita su demanda, es decir, solo para el inicio del proceso, afrontaría plazos de dos a cuatro meses y en ese lapso ¿qué pasaría fuera de la esfera judicial? ¿Los socios realizarían juntas, proyectos de inversión, adquisición de activos? Incluso podría darse el caso que

3 Artículo 153.- Proveimiento a escritos. Los escritos se proveen dentro de las cuarentiocho horas de su presentación, bajo responsabilidad. Es prohibido expedir resoluciones dilatorias que no guarden relación con el sentido del pedido, bajo responsabilidad.

4 Boletín Estadístico Institucional N 04-2018, emitido por la Gerencia General del Poder Judicial.

${ }^{5}$ https://laley.pe/art/7369/la-carga-procesal-del-poder-judicial-es-de-mas-de-3-millones-de-expedientes 
hasta que culmine el proceso de años, ya la sociedad se haya extinguido. Con estos plazos, se tiene que un proceso judicial por las causales descritas podría tener una duración no menor de dos años y ello sin considerar el tiempo en la Corte Suprema.

Si deseáramos aplicar la Teoría de los Juegos donde los jugadores se establecerían por el tiempo de trámites, y las opciones serían el proceso único de ejecución y el otro proceso de exclusión. Considero que la sociedad no aplicaría ninguna estrategia porque las dos dan resultados pésimos en cuanto a tiempo, no existe aquí ni un óptimo de Pareto ni un equilibrio de Nash, simplemente como pasa en la realidad, las sociedades se mantienen inertes y deciden no realizar ninguna acción.

\section{ANÁLISIS DE LA PROPUESTA RESPECTO AL STATUS-QUO}

Nuestra propuesta radica en modificar la estructura normativa de la Ley General de Sociedades, considerando que los hechos económicos no siempre deben ser regulados y las soluciones a los conflictos que se originen de ellos pueden solucionarse de mutuo acuerdo siempre y cuando no se haya cometido un hecho ilícito. En ese orden de ideas, del problema se deduce que las normas rígidas producen los inconvenientes descritos, es decir por aplicarse sólo Hard Law, la propuesta plantea el uso de normas flexibles que permitan dar un dinamismo a las sociedades, es decir el uso del Soft Law.

Las diferencias respecto al status-quo que presenta la propuesta (legal), sería entonces la siguiente:

\section{HARD LAW -LGS}

1. No permite sociedades de una persona a pesar del capital

2. No permite solución de conflictos entre socios en diversos temas o permite la exclusión de utilidades a los socios capitalistas.

3. Entre otras normas imperativas que dificultan la actividad empresarial.

\section{SOFT LAW-NLGS}

1. Permite la sociedad unipersonal

2. Permite la solución de conflictos en junta sin importar el porcentaje de acciones por indicios de ilícitos penales.

3. Permite la exclusión de utilidades a los socios capitalistas por beneficio de la sociedad.

4. Agiliza la actividad empresarial

La propuesta legal de aplicar el Soft Law en el tratamiento normativo para las sociedades, es una iniciativa que algunos países ya han adoptado, por cuanto realizando un estudio comparativo vemos que países como Nueva Zelanda ya ha flexibilizado sus normas y se ha convertido en el mejor país para hacer negocios en el 2019 según Doing Business ${ }^{6}$ las razones principales se basan en las siguientes:

1. Apertura de un negocio: Nueva Zelanda hizo más fácil iniciar un negocio por lo que es posible completar el proceso de registro en una línea simple en menos de un día.

2. Pago de impuestos: Nueva Zelanda hizo el pago de impuestos menos costosas para las empresas mediante la reducción de la tasa de impuesto de sociedades.

${ }^{6}$ https://datosmacro.expansion.com/negocios/doing-business 
3. La resolución de la insolvencia: Nueva Zelanda introdujo un procedimiento de reorganización con el objetivo de ofrecer una alternativa a la liquidación y quiebra y maximizar las posibilidades de continuar como negocio en marcha de una empresa.

En Latinoamérica no estamos en una buena situación México es el mejor país para realizar negocios ocupando el puesto 54, mientras que Perú desciende al puesto 68 según el referido informe, parece ser que la razón más importante es la demora en realizar los trámites y la riguridad de la documentación que se solicita a las sociedades, como se desprende de los tiempos señalados en el informe por ejemplo Nueva Zelanda constituye la sociedad en un sólo día en cambio en el Perú es un promedio de 27 días, así como los otros factores señalados como pago de impuestos por ejemplo, por ello debemos dar un tratamiento a las sociedades en función al hecho económico y no al hecho jurídico, vale decir, el Derecho en función de la actividad económica como ente regulador y no orientado a la creación de normas que las sociedades deben adecuarse para su constitución, funcionamiento y salida ordenada del mercado. Por ello, el Soft Law es vital para la creación de normas como lineamientos adecuados a las conductas empresariales, si existiese hechos contrarios a la Ley y abusos entre los insiders o tal vez con outsirders, el Derecho al ser uno sólo podrá regular estas malas conductas a través de las disciplinas del Derecho Público.

\section{3. ¿AUMENTA EL NIVEL DE BIENESTAR DE LA SOCIEDAD GRACIAS A SU PROPUESTA DE CARÁCTER LEGAL? ¿DE QUÉ MODO?}

El incremento del nivel de bienestar de una sociedad con el cambio normativo de Hard Law a Soft Law, produciría los siguientes beneficios:

\section{Efectos Directos:}

1. Apertura de un negocio en plazos menores.

2. Solución de controversias entre socios.

3. Acciones de Salvataje Empresarial: Mantenimiento de la sociedad en el mercado.

\section{Efectos indirectos:}

1. Aumenta la demanda de trabajo.

2. Aumenta la producción y beneficia a los consumidores por la competencia leal.

\section{CONCLUSIONES}

PRIMERA: EI Derecho se adecua a la realidad y no viceversa al pretender regular la actividad económica partiendo de la norma.

SEGUNDA: El hecho económico en las sociedades debe ser regulado de forma permisiva a través de la LGS. Si existiese algún hecho ilícito por parte de los socios se recurre a las reglas del Derecho Común no en la propia Ley.

TERCERA: El hecho económico no necesariamente debe ser regulado en todos los casos, existen los hechos alegales que generan riqueza y tienen un tratamiento de carácter general. 


\section{BIBLIOGRAFÍA BÁSICA:}

- $\quad$ ANGEL CABO, Natalia, "La Discusión en Torno a las Soluciones de Soft Law en Materia de Responsabilidad Social Empresarial”. Revista de Derecho Privado, Octubre de 2008.

- ALONSO GARCÍA, R.: "El Soft Law Comunitario", Revista de Administración Pública, Madrid, Num. 154, Enero- Abril 2001, pp.63-94

- DEL TORO HUERTA, M.I.: "El fenómeno del soft law y las nuevas perspectivas del Derecho Internacional", Anuario Mejicano de Derecho Internacional, vol. VI, 2006, pp. 513- 549.

- HERNANY VEYTIA. "Lex Negotii: El Nuevo Derecho Corporativo". Revista de Economía y Derecho Vol. 03 N 10 (Otoño 2006) Editorial Copyriht Sociedad de Economía y derecho UPC

- MARTÍNEZ-ORTIZ, Juan José, "El Gobierno Corporativo en el Perú: Contribución Para Enfocar el Concepto.", Revista de Economía y Derecho Vol. 04 Nº 14 (Otoño 2007) Editorial Copyriht Sociedad de Economía y derecho UPC.

- MAZUELOS BELLIDO, A.: "Soft Law, ¿Mucho ruido y pocas nueces ?", Revista Electrónica de Estudios Internacionales, num.8, 2004, pp.1-40.

- SARMIENTO, D.: "La autoridad del Derecho y la naturaleza del soft law", Cuadernos de Derecho Público, n² 28, 2006, pp. 221-261.

Fecha de recepción: 30 de abril de 2019

Fecha de aceptación: 16 de junio de 2019 